\title{
FRACTURE OF ABUTMENT SCREW SUPPORTING A CEMENTED IMPLANT-RETAINED PROSTHESIS WITH EXTERNAL HEXAGON CONNECTION: A CASE REPORT WITH SEM EVALUATION
}

\author{
Mariana Diniz Bisi SANTOS ${ }^{1}$, Arthur Braga PFEIFER ${ }^{1}$, Marcos Rogério Pupo SILVA ${ }^{1}$, \\ Claudio Luiz SENDYK ${ }^{2}$, WIIson Roberto SENDYK ${ }^{3}$
}

1- DDS, MsC, Graduate student, Department of Implantology, University Santo Amaro, São Paulo, São Paulo, Brazil.
2- DDS, MSc, PhD, Associate Professor, Department of Prosthodontics, University of São Paulo, São Paulo, São Paulo, Brazil.
3- DDS, MSc, PhD, Associate Professor, Department of Implantology, University Santo Amaro, São Paulo, São Paulo, Brazil.

Corresponding address: Mariana Diniz Bisi dos Santos - Rua Diogo Moia, n 380, apt 1601, Umarizal - 66055-170, Belém, PA, Brazil Phone 559132230237 or 559199822502 - e-mail:marianabisi@hotmail.com

Received: December 13, 2006 - Modification: March 16, 2007 - Accepted: April 13, 2007

\begin{abstract}
$O$

ne of the causes of implant failures in cemented implant-retained prostheses is the fracture of abutment screw or UCLA abutment. This article reports a case of simultaneous fracture of two UCLA abutments screws occurring in an implantsupported prosthesis placed in the mandibular molar region. The fractured structures were examined under scanning electron microscopy to investigate the probable causes of the failure, which were not related to failures on materials or fabrication of the screws, but rather were due to shear forces. The misfit in cemented prostheses may be the most likely cause of shear force generation.
\end{abstract}

Uniterms: Osseointegrated implants; Dental abutments; Fractures; Prostheses and implants.

\section{INTRODUCTION}

Failures of osseointegrated implants have been associated with many factors, such as poor bone quality, lack of initial instability, overloading and fractures of implants and abutment screws ${ }^{10}$. Fracture of these elements may be related with a poor fit of the framework, which leads to material fatigue, occlusal overload and intrinsic material failures ${ }^{10,16}$.

The increasing use of implants in the rehabilitation of partially edentulous patients has widened the possibilities in Prosthodontics with the introduction of new concepts, such as the placement of implant-supported prostheses, which can be either retained by screws or cemented.

Metal fractures may be related to microstructures that influence the material properties, which are related with the localized identification of chemical phases and segregations, frequently associated with failures at interfaces or components, which, in turn, can cause the fractures ${ }^{5}$. These aspects may be investigated by scanning electron microscopy (SEM) and may play a key role on the failure of prosthetic components.

This article reports a case of simultaneous fracture of two UCLA abutments screws occurring in an implantsupported prosthesis placed in the mandibular molar region. The fractured structures were examined by SEM to investigate the probable causes of the failure.

\section{CASE REPORT}

A 40-year-old non-smoker female patient in good general health conditions attended a private dental clinic with two Branemark implants (unknown trademark) in function for about 2 years. The implants were placed in the posterior left side of the mandible, corresponding to the mandibular left second premolar $(3.75$ X $10 \mathrm{~mm})$ and first molar $(3.75 \mathrm{X}$ $7.5 \mathrm{~mm}$ ), joined by the structure of a metal-ceramic fixed partial denture. The UCLA abutment screws were fractured and the crowns were dislodged. The crows were cemented to the abutments and exhibited visible misfit, mainly on the distal implant. There was no radiographic evidence of marginal bone loss. After several unsuccessful attempts to remove the fractured screw fragments, it was decided to remove the implants. The fractured components were further analyzed with a scanning electron microscope (FEI Philips 
XL-30, Eindhoven, The Netherlands) to assess the structural failures.

Failure analysis by SEM demonstrated the occurrence of two moments of rupture in the first fractured implant (mesial), corresponding to the mandibular left second premolar, with evidence of ductile fracture due to shear strength, as demonstrated by the first line, followed by compression (Figures 1 to 3 ).

In the second implant, the fracture was characterized by a strong torsional component, with fewer compressive evidences and characteristics of final fracture due to the presence of "dimples", also called alveolar-like structures. There were no signs of failure in the material or screw fabrication (Figures 4 and 5).

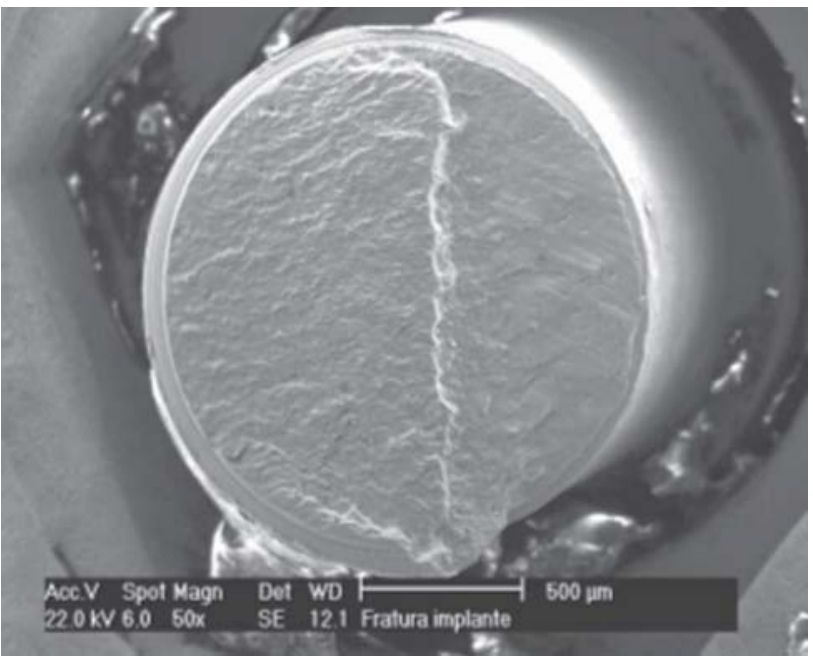

FIGURE 1- First fractured screw (initial fracture caused by shear and compressive strengths). The step demonstrates fracture in two phases

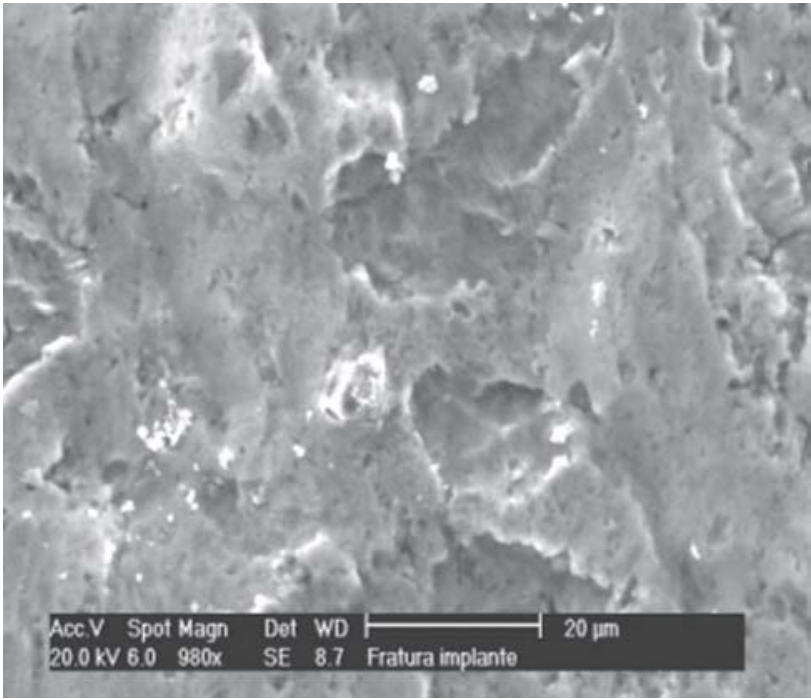

FIGURE 2 - Higher magnification of the initial fracture reveals the squashing caused by compressive strengths and absence of "dimples", which characterizes that this was the first portion to fracture, and chewing promoted surface smoothing until occurrence of fracture of the first implant at the same time

\section{DISCUSSION}

Studies on the biomechanics of implants have historically concerned about screw-retained prostheses, with limited scientific analysis of cemented prostheses, in spite of their

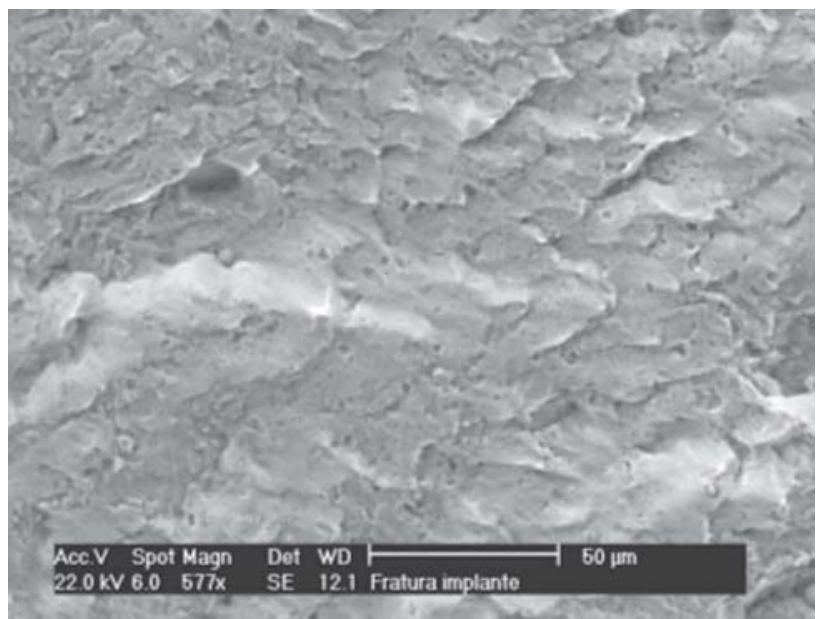

FIGURE 3 - Higher magnification of the first step, revealing wave-shaped irregularities, characteristic of fracture due to shear forces

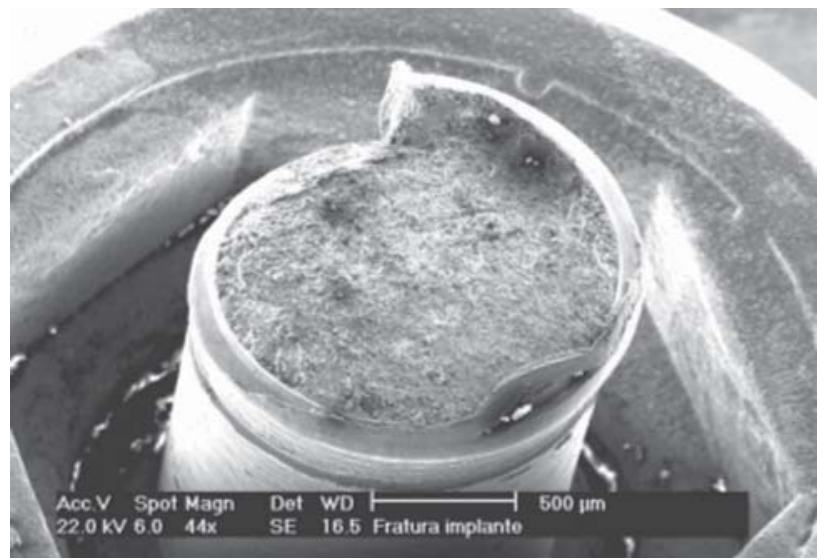

FIGURE 4 - Second fractured screw

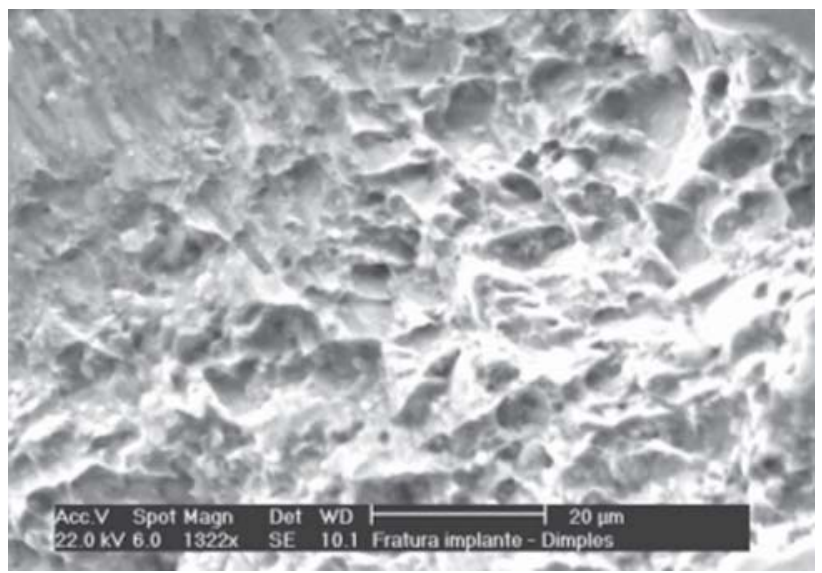

FIGURE 5 - Fractured surface of the second screw with "dimples", with alveolar-like appearance, which characterizes final fracture at a single time due to torsion 
frequent use. The efficacy of cemented dentures has been questioned because it is different from the protocols described by Branemark. The UCLA abutment has been used to support cemented prostheses in single implants or fixed dentures. There are currently several types of titanium and ceramic abutments for use in prostheses cemented over single implants ${ }^{4}$.

Screwed prostheses have been designed to promote integrity of the connection between prosthesis, abutment and implant. Rieder ${ }^{13}$ (1990) and later Hebel and Gajar ${ }^{8}$ (1997) stated that esthetics and occlusal function would be the reasons for use of cemented prostheses. It has also been advocated that passive fit between the prosthetic crown and the abutment is more easily obtained in cemented dentures because the cement would fill the interfacial gaps, thus improving the load transmission to the prosthesis/ implant/bone system ${ }^{11}$.

The passivity of restorations is essential for a successful implant-prosthetic rehabilitation ${ }^{4-8,11,14-16}$. According to Jemt and Book $^{9}$ (1996), prosthetic misfit might not be much significant because the average distortion in their study was $100 \mu \mathrm{m}$ and no passivity was observed in the analyzed restorations. In addition, no significant correlation was found between the lack of passivity and bone loss. These authors suggested that misfit is more related to prosthetic failures due to the ankylotic nature of osseointegration.

It has been reported that a misfit equal to or higher than $30 \mu \mathrm{m}$ can be considered dubious or unacceptable ${ }^{2}$. Restorations with $26 \mu \mathrm{m}$ or less of misfit are considered as "passive fit". Guinchet ${ }^{6}$ compared the integrity and load transmission of cemented and screwed prostheses and concluded that, after function, the marginal gap of screwed dentures was significantly smaller than that of cemented prostheses. The load transmission of screwed prostheses was higher yet transmitted to the apical portion of the implant, while in cemented prostheses it was lower yet concentrated at the coronal portion of the implant. The smaller marginal gap of screwed prostheses is related to a higher load transmission, and the greater marginal gap of cemented prostheses is related to a lower load transmission.

There are no research-based evidence of the effect of misfit on osseointegration failure and the risk it poses to implant success. However, there are evidences that misfit increases the occurrence of mechanic failures of components and/or fracture.

Several studies have addressed the effect of occlusal overload on implants, although no scientifically based data are available. The tolerance between mechanic components allows short movements at the interfaces, and flexural fatigue plays an important role on denture long-term success. The potential of non-axial strengths to cause plastic deformations, wear or failures due to fatigue of prosthetic components is clearly dependent on the design and material used.

The placement of implants on posterior mandibular regions, close to the temporomandibular joint, yields an unfavorable condition due to the magnitude of load transmission in this area. Likewise, the wide occlusal platform avoids load transmission following the implant long axis.

Guichet, et al. ${ }^{7}$ (2000) compared the relationship between marginal discrepancies and the passive fit of screwed and cemented prostheses in fixed partial prostheses by microscopic analysis and did not find differences after final screw torque and cementation.

Sendyk and Sendyk ${ }^{16}$ (1998) demonstrated the load distribution of osseointegrated implants using finite element analysis and concluded that load transmission in screwed prostheses is often concentrated at the gold screw attaching the crown to abutment, which acts as a safety device. In cemented prostheses, the cement and abutment screw receive this load, mainly shear forces. In the same study, these authors did not find significant differences between the use of resin or ceramic in the occlusal platform.

A previous study ${ }^{3}$ on the registration of force development with ceramic and acrylic resin occlusal materials on implant-supported prostheses, both in vivo and in vitro, found differences only when load transmission was assessed in vitro.

The review of literature on Implantology and Prosthodontics is not conclusive with regard to the causes of failures and complications associated with prosthetic treatments with osseointegrated implants. The lack of passive fit and generation of shear forces are the most frequently reported causes of biomechanical failures of implants.

\section{CONCLUSIONS}

In the case reported in this article, the causes of fractures were not related to failures on materials or fabrication of the screws, but rather were due to shear forces. The misfit in cemented prostheses may be the most likely cause of shear force generation.

\section{REFERENCES}

1- Adell R, Lekholm U, Rockler B, Branemark PI. A 15-years study of osseointegrated implants in the treatment of the edentulous jaw. Int J Oral Surg. 1981;10:387-416.

2- Assif D, Marshak B, Schmidt A. Accuracy of implant impression techniques implants. Int J Oral Maxillofac Implants. 1996;11(2):21622

3- Bassit R, Lindstrom H, Rangert B. In vivo registration of force development with ceramic and acrylic resin occlusal materials on implant-supported prostheses. Int J Oral Maxillofac Implants. 2002;17(1):17-23

4- Binon PP. Implants and Components: Entering the new millennium. Int J Oral Maxillofac Implants. 2000;15(1):76-94.

5- Eckert SE, Steven EE, Meraw SJ, Cal E, Ow RK. Analysis of incidence and associated factors with fracturedd implants: a retrospective study. Int J Oral Maxillofac Implants. 2000;15(5):6627. 
6- Guichet DL. Load transfer in screw and cement-retained fixed partial denture designs. J Prosthet Dent. 1994;72:361.

7- Guichet DL, Caputo AA, Choi H, Sorensen JA. Passivity of fit and marginal opening in screw or cemented-retained implnt fixed partial denture designs. Int J Oral Maxillofac Implants. 2000;15(2):239-51.

8- Hebel KS, Gajjar RC. Cement-retained versus screw-reteined implant restorations: achieving optimal occlusion and esthetics in implant dentistry. J Prosthet Dent. 1997;77:28-35.

9- Jemt T, Book K. Prosthesis misfit and marginal bone loos in osseointegrated implant patients. Int J Oral Maxillofac Implants.1996;11:620-5

10- Kronstrom M, Svenson B, Hellman M, Persson GR. Early Iimplant failures in patients treated with Branemark system titanium dental implants: a retrospective study. Int J Oral Maxillofac Implants. 2001;16(2):201-7.

11 - Misch C. Screw-retained versus cemented-retained implant supported prosthesis. Pract Periodontics Aesthet Dent. 1995;9:158 .

12 - Rangert B, Jemt T, Jorneus L. Forces and moments on Branemark Implants. Int J Oral Maxillofac Implants.1989;4(3):241-7.

13-Rieder CE. Copings on tooth and implant abutments for superstructure prostheses. Int J Periodontics Restorative Dent. $1990 ; 10(6): 437-53$

14-Sendyk CL. Distribuição das tensões nos implantes osseointegrados: análise não linear em função do diâmetro do implante e do material da coroa protética [tese]. São Paulo (SP): University of São Paulo; 1998.

15-Sendyk WR, Sendyk CL. Aplicações clínicas dos implantes osseointegrados. In: Todescan F, Bottino MA, organizadores. Atualização em clínica odontológica. São Paulo: Artes Médicas; 1996. p. 299-341.

16- Sendyk WR, Sendyk CL. Restaurações totais fixas: planejamento e execução. In: Dinato $C$, Polido W, organizadores. Implantes osseointegrados: cirurgia e prótese. São Paulo: Artes Médicas; 2001. p. $215-48$

17- Setz J, Kramer A, Benzing U, Weber H. Complete dentures fixed on dental implants: chewing patterns and implant stress. Int J Oral Maxillofac Implants1989;4(2):107-11.

18- Taylor TD, Agar JR, Vogiatzi T. Implant Prosthodontics: current perspective and future directions. Int J Oral Maxillofac Implants. $2000 ; 15(1): 66-75$ 